The Psychological Record, 2009, 59, 551-562

\title{
DEPRESSIVE REALISM: WISER OR QUIETER?
}

\author{
Fernando Blanco, Helena Matute, and Miguel A. Vadillo \\ Deusto University, Bilbao, Spain
}

\begin{abstract}
Depressive realism consists of the lower personal control over uncontrollable events perceived by depressed as compared to nondepressed individuals. In this article, we propose that the realism of depressed individuals is caused not by an increased accuracy in perception, but by their more comprehensive exposure to the actual environmental contingencies, which in turn is due to their more passive pattern of responding. To test this hypothesis, dysphoric and nondysphoric participants were exposed to an uncontrollable task and both their probability of responding and their judgment of control were assessed. As was expected, higher levels of depression correlated negatively with probability of responding and with the illusion of control. Implications for a therapy of depression are discussed.
\end{abstract}

Keywords: depression, judgment of control, probability of responding, illusion of control

Under certain conditions, people tend to overestimate the relationship between their actions and reinforcers, even if these events occur noncontingently. Langer (1975) called this phenomenon the illusion of control, because it consists of people believing that they have personal control over uncontrollable events. The idea that sometimes people perceive contingencies in a nonrealistic way had been proposed long ago (e.g., Ward \& Jenkins, 1965), and since Langer's seminal article on the illusion of control, many researchers have replicated this effect under very different conditions (e.g., Alloy \& Abramson, 1979; Matute, Vadillo, Vegas, \& Blanco, 2007; Rudski, Lischner, \& Albert, 1999). A very influential article was Alloy and Abramson's; they found that college students who were mildly depressed tended to show less illusion of control than nondysphoric students. This new effect was called depressive realism and it is of much theoretical and practical importance: Traditional theories of depression had often associated perceptual

Support for this research was provided by Dirección General de Investigación of the Spanish Government (Grant SEJ2007-63691/PSIC), Departamento de Educación, Universidades e Investigación of the Basque Government (Grant PI2008-9), and Dirección General de Investigación, Tecnología y Empresa of the Junta de Andalucía (Grant SEJ-406). Fernando Blanco was supported by fellowships BFI081.020.0 and BFI04.484 from Gobierno Vasco. He is now at the University of Leuven, Belgium. We thank Gumersinda Alonso, Esther Calvete, Francisco J. López, Rachel Msetfi, Dominique Muller, Robin Murphy, Serban C. Musca, Cristina Orgaz, Juan M. Rosas, and David Watson for their valuable comments and discussions on preliminary versions of this article.

Correspondence concerning this article should be addressed to Helena Matute, Departamento de Psicología, Universidad de Deusto, Apartado 1, 48080 Bilbao, Spain. E-mail:matute@fice.deusto.es 
distortions with depressed personality (Beck, 1967), but the finding that depressed individuals are more realistic in their detection of noncontingency contradicts this view.

In addition to depression, studies in the area of contingency judgments have detected many other variables that modulate the illusion of control. Some interesting examples are the percentage of reinforcement, also called outcome density (Alloy \& Abramson, 1979; Matute, 1995; Rudski et al., 1999), skill-related factors (Thompson, Armstrong, \& Thomas, 1998), valence of outcomes (Aeschleman, Rosen, \& Williams, 2002; Alloy \& Abramson, 1979), length of the intertrial intervals (Msetfi, Murphy, \& Simpson, 2007; Msetfi, Murphy, Simpson, \& Kornbrot, 2005), number of trials (Shanks \& Dickinson, 1987), delay of reinforcement (Rudski, 2000), and probability of responding (Matute, 1996). The present research is concerned with this latter factor. In Matute's (1996) experiment, instructions given to participants made them more or less likely to respond in order to produce the outcome, which was response independent. According to Matute (1996), in order to be able to detect that an outcome occurs with the same probability regardless of whether participants respond or not, participants must respond with a probability of 0.5 or close to it. That is, only by responding in $50 \%$ of the trials can participants be exposed to (and detect) what happens both when they respond and when they do not respond. By contrast, as the probability of responding approaches 1, it becomes more difficult to notice that the events could have occurred with the same probability in the absence of responding. Matute's (1996) results confirmed this prediction: The variations in the probability of responding that were induced through instructions in a regular student sample positively correlated with the illusion of control. Although she did not study differences between depressed and nondepressed participants, a straightforward prediction of this approach is that the passivity and low probability of responding that is usually associated with depression (Lewinsohn, Sullivan, \& Grosscup, 1980) could be responsible for the accuracy of depressed individuals in detecting the absence of control (see also E. Skinner, 1985). The present research provides a direct test for this hypothesis.

Let us illustrate this mechanism with an example. Imagine an athlete who always performs his or her personal "magical ritual of victory" the night before taking part in a competition. Like almost anyone, this athlete sometimes obtains a good result and sometimes a bad result. Obviously, no connection between performing the ritual and winning or losing the competition exists. However, if the ritual is performed at every opportunity, it is impossible to know whether the ritual has any effect, because the athlete will lack a critical piece of information: the probability with which the reinforcer would have occurred if the ritual had not been performed. If the athlete wins, for example, $80 \%$ of the time, and he or she always performs the ritual the night before the competition (so the probability of responding is 1), then the ritual will show an apparent strong effect on the athlete's achievement. But, if the athlete had never performed the ritual, or at least had reduced its execution to, say, $50 \%$ of the trials, he or she would have realized that he or she still could win $80 \%$ of the time. It would be easy to conclude in that case that the good results obtained are not an effect of the magical influences of the ritual. It seems clear, thus, 
that perceived contingency is affected by the probability of responding. Indeed, most experiments showing that participants are able to accurately detect an absence of contingency have explicitly instructed the participants to respond in about 50\% of the trials (see, e.g., Shanks \& Dickinson, 1987; Wasserman, 1990).

In essence, what we are suggesting is not too different from B.F. Skinner's (1948) depiction, in his classic experiment on superstition in the pigeon, of adventitiously reinforced behavior. Indeed, in a context in which a noncontingent reinforcer is occurring at a high rate, the more the animal (or human) responds, the greater the chances that responses and reinforcers will coincide. Skinner's experiments with pigeons were strongly criticized by research showing that his results could be better explained as Pavlovian conditioning than as superstitious instrumental behavior (e.g., Staddon \& Simmelhag, 1971). This problem, however, does not invalidate the idea that the more active a person is, the greater the chances that his or her behavior will be reinforced in situations in which the reinforcer is occurring adventitiously. What we suggest is simply that the illusion of control is strongly based on these response-reinforcer coincidences. And, by the same reasoning, it follows that depressive individuals, who are generally less active, should be less prone to experiencing adventitious reinforcers and thus less vulnerable to the illusion of control. The main purpose of the present research was, therefore, to test the hypothesis that depressive realism is due, at least in part, to the low response rate of depressed participants. Although the relationship between activity and depression in response-contingent situations is well known (Lewinsohn, 1974; Lewinsohn et al., 1980), what we aim to test here goes beyond this point: The lower activity not only reduces the chances to obtain response-contingent reinforcers but also reduces the chances that noncontingent reinforcers will coincide with the participant's responses. Thus, lower activity reduces the chances that the participant can develop an illusion of control.

An additional purpose of this experiment was to test for the generality of the effect. Given that most, if not all, studies on the depressive realism effect have been conducted with college students (and particularly with psychology students), one may wonder whether the effect is a laboratory artifact that is restricted to those very artificial and controlled situations. For this reason, we decided to use the Internet as our research arena, to test for depressive realism in a less restricted environment.

\section{Overview of the Experiment}

Participants first completed the Beck Depression Inventory (BDI; Beck, Ward, Mendelson, Mock, \& Erbaugh, 1961) and were classified as either dysphoric or nondysphoric. Then, both groups of participants were asked to produce an outcome on the computer screen by pressing the space bar in a task where the outcomes were actually programmed to occur independently of their behavior. At the end of the experiment we asked participants to rate their degree of perceived control over the outcome. If our hypothesis is correct, we should observe both a lower probability of responding and a lower illusion of control in dysphoric, as compared to nondysphoric, individuals. 


\section{Method}

\section{Participants and Apparatus}

Sixty-six participants took part in the experiment via the Internet. All were anonymous volunteers who visited our virtual laboratory (www.labpsico .com) and decided to take part in the experiment. To increase participation in the experiment, and following ethical standards for human research over the Internet (Frankel \& Siang, 1999), we did not ask participants to provide any personal data, nor did we use cookies or software to obtain involuntary personal information from them. Nevertheless, and although the use of an Internet-based methodology is not yet very common in mental health research, the advantages and disadvantages of Web-delivered experiments have been well studied and documented. Admittedly, it is difficult to ensure that all constraints are met as in a traditional laboratory, but the potential problems are well known and several solutions have been worked out (see, e.g., Reips, 2002). It is hard to ensure, for instance, that no participants took the experiment more than once. However, they should be too bored to do so. Even so, if this were to ever happen, the main consequence would be that it would be impossible to replicate the standard laboratory result, and this is very easily detected. For this reason, a replication of the basic laboratory result is the first control that we request; only after we are sure that our experiment replicates the basic laboratory effect (in the present case, the depressive realism effect) will we trust any other additional results that we may get from the Internet sample. Using this general approach, very similar results are generally being reported when the same experiment is reproduced in the laboratory and through the Internet (see, e.g., Birnbaum, 2000; Buchanan, \& Smith, 1999; Gosling, Vazire, Srivastava, \& John, 2004; Kraut, Olson, Banaji, Bruckman, Cohen, \& Couper, 2004; Matute, Vadillo, Vegas, \& Blanco, 2007; Steyvers, Tenenbaum, Wagenmakers, \& Blum, 2003; Vadillo, Bárcena, \& Matute, 2006; Vadillo \& Matute, 2007). Therefore, and as a means of controlling for possibly noisy data in this experiment, we will check that the results replicate the basic depressive realism effect before we move on to study the effect of our target variable, the probability of responding.

Participants were classified as either dysphoric or nondysphoric, as a function of their direct BDI scores. Those with a direct score of 9 or above were included in the dysphoric group, whereas participants who scored below 9 were assigned to the nondysphoric group. This cutoff point was the same already used in many other studies about depressive realism (e.g., Alloy \& Abramson, 1979; Msetfi et al., 2005) and implies not a clinical categorization but, rather, a common way to identify mildly depressed individuals among a typical population of college students (this is the reason why we prefer to use the term dysphoric instead of depressed). This resulted in the classification of 41 participants as nondysphoric and 25 as dysphoric. Mean BDI scores were $3.68(M S E=0.36)$ in the nondysphoric group and $17.88(M S E=1.26)$ in the dysphoric group.

\section{Procedure}

Before the experiment began, participants completed the BDI (Spanish adaptation by Conde, Esteban, \& Useros, 1976), which is often used in the 
depressive realism literature as a depression measure (e.g., Alloy \& Abramson, 1979). Its purpose in this type of experiment is not to detect clinically depressed individuals but to provide a simple and rapid identification of mild depression or dysphoria in a normal population. After completion, a message told participants that scores and feedback would be presented at the end the experiment. This was done in this way so that the feedback could not affect performance during the experiment.

The experimental task was an adaptation of the one used by Matute (1996), except that, in order to facilitate its execution over the Internet, the participants were requested to produce visual images (blue flashes) on the computer screen rather than to escape from noise. This version had already been successfully tested for the illusion-of-control effect, both in our laboratory and through the Internet, with very similar patterns of results in both cases (see Matute, Vadillo, \& Bárcena, 2007; Matute, Vadillo, Vegas, \& Blanco, 2007; a demonstration of this program, including source code, can be downloaded from our Web site, http://www.labpsico.com). A translation from Spanish of the instructions used in this experiment reads as follows:

In this experiment you will see some blue flashes on your monitor from time to time. When they appear, they have a fixed duration of $1 \mathrm{~s}$. Your task will be to make them appear. That is, YOU WILL BE TRYING TO KEEP THE MONITOR SCREEN BLUE as much of the time as possible. In order to do so, you will have to do something very rapidly with the space bar each time that a flash finishes. If you do it RIGHT, the flash will show up again very rapidly. If you do it WRONG, the flash will stay off for $5 \mathrm{~s}$.

A total of 50 flashes were presented, and all of them had a fixed duration of $1 \mathrm{~s}$. There was no actual contingency between pressing the space bar and the occurrence of the flashes, which were presented on a preprogrammed schedule with short (1-s) and long (5-s) intervals between flashes. According to the instructions, the participants' goal was to make the flash show up again very rapidly every time it turned off. Thus, the 1-s intervals were planned to work as (noncontingent) positive reinforcement, whereas the 5-s intervals should work as nonreinforced trials. Regardless of whether the participant responded, the task was programmed in such a way that $75 \%$ of the intervals between the flashes lasted $1 \mathrm{~s}$ and the other 25\% lasted $5 \mathrm{~s}$. This high percentage of reinforcement, with prevalence of short intervals, should favor the development of the illusion of control, as it is well known that a higher percentage of reinforcers produces stronger illusions (Allan, Siegel, \& Hannah, 2007; Alloy \& Abramson, 1979; Matute, 1995). The important point, however, is that, according to our hypothesis, coincidences between responses and reinforcers should be more frequent in nondysphoric than in dysphoric people-because the probability of responding would be higher in nondysphoric participants. This, in turn, should produce the greater accuracy of dysphoric participants in detecting the null contingency. Responses on the space bar were collected to test whether dysphoric participants did actually have a lower probability of responding, which we defined as the number of trials in which there was at least one response divided by the total number of trials.

After the 50 scheduled flashes, the judgments of control were assessed via the following question, which was presented on the middle of the screen: To what extent do you think you have controlled the onset of the flashes? The 
answers were given by clicking on scale of 0 to $100(0=I$ did not control it, $100=I$ controlled $i t)$. Given that the present experiment resembled a zerocontrol condition in which the outcomes are programmed to occur, regardless of whether the participant responds or not, a judgment of control would be more realistic the closer it is to zero. Finally, once the participants had provided their causal rating, they were shown their BDI score, together with a brief explanation of the purpose of the experiment and a reminder that the questionnaire was used for research purposes only and that those interested in a serious clinical assessment should visit a psychologist in person.
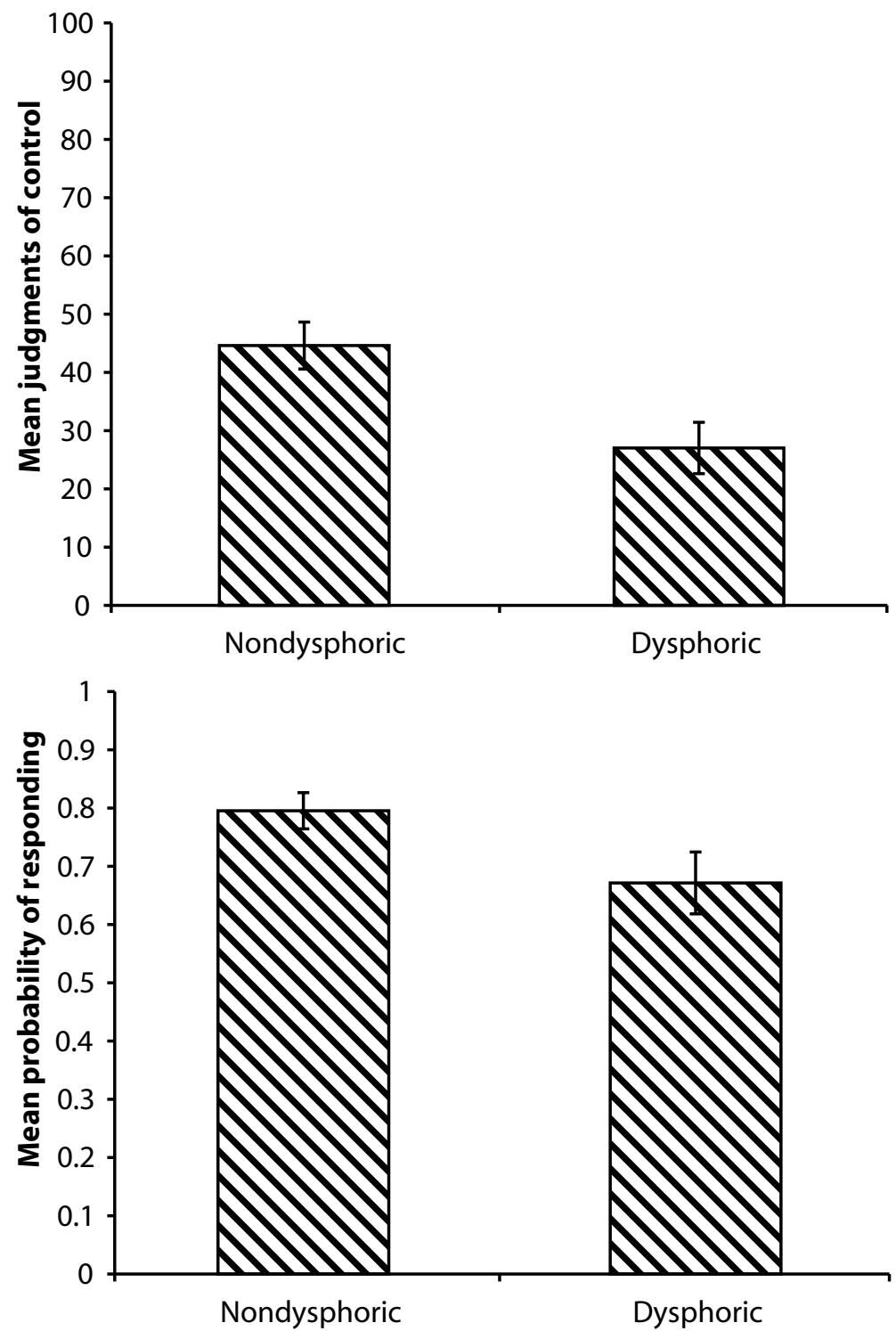

Figure 1. Mean judgments of control (upper panel) and mean probability of responding (lower panel) for dysphoric and nondysphoric participants. Error bars show the standard error of the mean. 


\section{Results}

The results of this experiment show that, as expected, dysphoric participants were more passive and produced lower judgments of control about noncontingent reinforcers than nondysphoric participants.

The upper panel of Figure 1 shows the mean judgments of control for both dysphoric and nondysphoric participants. A one-way ANOVA detected a significant effect of mood on judgments, $F(1,64)=19.03, p<.001$, with dysphoric participants being more realistic than nondysphoric ones. Additionally, we found a negative correlation between BDI scores and judgments of control, $r=-.32, p<.001$. These converging results indicate that we successfully replicated the depressive realism effect with an Internet sample.

In addition, the following analyses show that, as we anticipated, this depressive realism effect was mirrored by a differential level of responding in dysphoric and nondysphoric participants. The lower panel from Figure 1 shows the mean probability of responding in both groups. A one-way ANOVA showed a significant effect of mood on the probability of responding, $F(1,64)$ $=7.47, p<.01$ : Dysphoric participants showed a lower activity level (implying more passivity) than nondysphoric participants. In addition, correlational analyses showed a significant negative correlation between BDI score and probability of responding, $r=-.306, p<.01$ (i.e., the greater the BDI score, the lower the probability of responding), and, more interesting, a significant positive correlation between probability of responding and judgment of control, $r=.32, p<.01$ (i. e., the lower the probability of responding, the lower the judgment of control).

\section{Discussion}

Since Alloy and Abramson's seminal work in 1979, depressive realism has been a fertile research area and has provided interesting discussions among scientists (e.g., Ackermann \& DeRubeis, 1991; Allan et al., 2007; Alloy \& Clements, 1992; Haaga \& Beck, 1995; Matute, 1996; Msetfi et al., 2005). We have proposed that differential probability of responding, as a function of mood, plays a relevant role in depressive realism: In contrast to nondysphoric individuals, who tend to respond as much as they can to obtain a desired outcome, depressive individuals are more passive, and this provides them with more comprehensive exposure to what happens both when they respond as well as when they do not respond. Theirs is certainly a maladaptive behavior when one is trying to maximize reinforcement, but it happens to be the best possible strategy when one is trying to maximize accuracy in the detection of contingencies (see Matute, Vadillo, Blanco, \& Musca, 2007, for further theoretical elaboration and computer simulations on this point).

The results of this experiment supported our hypothesis: First, participants who scored higher on the BDI showed less illusion of control than the others, therefore replicating Alloy and Abramson's (1979) basic depressive realism effect. Moreover, recall that the participants were anonymous Internet users, which is indicative of the robustness of this effect. Second, the dysphoric participants were more passive, and tended to emit no responses in more trials than nondysphoric participants did. Finally, we have shown that participants with higher probability of responding were more vulnerable to the illusion of control than participants with a lower probability of responding. 
It is noteworthy that Matute (1996) obtained the reduction in the illusion of control by manipulating just the instructions given to participants, which encouraged two different levels of probability of responding. The reduction in the illusion of control that we obtained in the present experiment was induced by mood, not instructions, but the underlying mechanism is presumably the same: probability of responding. Thus, a clear prediction of our theory is that any manipulation that alters the probability of responding, be it a mood state, instructions, fatigue, drugs, exercise, or any other one, should be able to influence the actual exposure to environmental contingencies and, thereby, the subjective perception of control. In this sense, depression is neither necessary nor sufficient for depressive realism: A nondepressed person can show a realistic perception of uncontrollability if instructed to reduce his or her rate of responding (Matute, 1996), but, most importantly, our current results suggest that a depressed person could probably develop illusions of control if asked to increase his or her level of responding.

As noted by Plaud and Eifert (1998), given the high prevalence rates and human and financial costs associated with depression, it is not surprising that depression is a widely studied disorder and that so many different, and sometimes contradictory, behavioral and cognitive models of depression have been proposed (e.g., Beck, 1967; Lewinsohn, 1974; Rehm, 1977; Seligman, 1975). Lewinsohn, in one of the most widely cited studies of depression, argued that depression is due to a lack of reinforcers, whereas Seligman argued that it is not the lack of reinforcers but the lack of control over them that causes depression. The present results, together with those of Alloy and Abramson (1979) and many other experiments showing illusions of control and depressive realism effects, show that the lack of control over reinforcers is not even detected by human participants unless they are already depressed (see Matute, 1994, and Schwartz, 1981, for further elaboration on this point).

Traditional theories of the illusion of control and depressive realism have focused on personality and internal variables as explanations for these effects (e.g., Alloy \& Abramson, 1979; Haaga \& Beck, 1995). The theory we are proposing is perfectly compatible with these views, but it is framed in a more basic level of analysis. While agreeing that sadness and negativity do affect the perception of contingency, we suggest that the way they do it (or at least one of the ways) is by reducing the probability of responding. In other words, the reduction in the illusion of control that depressive individuals show is actually a secondary effect of the lower probability of responding that is associated with depressive mood. Of course, we cannot be sure about the direction of causality; it could well be that it is passivity that comes first, and it produces depression through a better exposure of the reinforcer's occurrences in the absence of responding (and, thus, a greater perception of the absence of control). In either case, increasing levels of activity has important implications for therapy, which we will next discuss.

Beck's (1967) characterization of depressive thinking as negative and pessimistic became the most extended framework for therapists, most of whom try to eradicate irrational bias in depressive thinking (see also Ellis, 1962). However, findings about depressive realism may change this generalized view. For example, they clearly show that certain biases and illusions are part of a healthy, nondepressed, and well-adapted mind, and that the lack of these biases, even though it leads to realism and objectivity, is associated with depression and maladaptation (e.g., Alloy \& Clements, 1992; Forgas, 1998; Taylor \& Brown, 
1988). These reports suggest that even in situations that are uncontrollable (e.g., an incurable illness), therapists should sometimes promote some degree of illusion-which is healthy and protects one from external stressors-instead of pursuing an objective, unbiased way of thinking.

In addition, if, as we have shown, probability of responding plays an important role in the illusion of control, then an important component of depression therapy should be to increase the activity level of depressed people. It is often easier to increase a patient's activity level than to increase his or her positive and optimistic cognitions. Increasing the individual's probability of acting even before he or she is able to see any relationship between behavior and desired outcomes should eventually increase the number of coincidences between responses and desired outcomes. Indeed, increasing the activity levels of depressed patients has long been recommended by behavior analytic theories on the grounds that the more a patient responds, the greater the opportunities to obtain response-contingent reinforcers (Lewinsohn, 1974; Lewinsohn et al., 1980). What our results show is that this approach is beneficial not only in controllable situations but, most importantly, in uncontrollable situations as well (see B. F. Skinner, 1948). The illusion of control that will probably result from this strategy is quite incompatible with depression and helplessness (see also Matute, 1994, 1996).

Of course, our suggestion is not without its risks. Sometimes, increasing the illusion of control can be dangerous. As an example, consider the case of individuals who prefer to believe in magical curative rituals than in scientific medicine in order to cure their diseases. However, increasing the probability of responding should be a very effective strategy when applied by rigorous and experienced psychologists. Indeed, it is a very adaptive strategy, not only as a means to increase illusions, but also as the most effective possible way to maximize reinforcers in controllable situations. As discussed above, it is generally much better to be active than to be passive when trying to maximize reinforcers.

Admittedly, our laboratory experiments, as most experiments in this area, were conducted with dysphoric participants, rather than clinically depressed individuals. Even so, these experiments suggest that to increase illusions and reduce depression, one of the variables that we can most easily manipulate is the patient's tendency to act. This is congruent with many behavior therapies that try to increase the activity levels of depressed patients. Our experiments show that this strategy is effective not only because by being active one can obtain more reinforcers in controllable situations, but also because even if the situation is uncontrollable, one can have the optimistic illusion of personal control. The next step should clearly be to conduct the studies with clinically depressed patients.

\section{References}

ACKERMANN, R., \& DERUBEIS, R. J. (1991). Is depressive realism real? Clinical Psychology Review, 11, 565-584.

AESCHLEMAN, S. R., ROSEN, C. C., \& WILLIAMS, M. R. (2002). The effect on non-contingent negative and positive reinforcement operations on the acquisition of superstitious behaviors. Behavioural Processes, 61, 37-45.

ALLAN, L. G., SIEGEL, S., \& HANNAH, S. (2007). The sad truth about depressive realism. Quarterly Journal of Experimental Psychology, 60, 482-495. 
ALLOY, L. B., \& ABRAMSON, L. Y. (1979). Judgment of contingency in depressed and non-depressed students: Sadder but wiser? Journal of Experimental Psychology: General, 108, 441-485.

ALLOY, L. B., \& CLEMENTS, C. M. (1992). Illusion of control: Invulnerability to negative affect and depressive symptoms after laboratory and natural stressors. Journal of Abnormal Psychology, 101, 234-245.

BECK, A. T. (1967). Depression: Clinical, experimental, and theoretical aspects. New York: Harper \& Row.

BECK, A. T., WARD, C. H., MENDELSON, M., MOCK, J., \& ERBAUGH, J. (1961). An inventory for measuring depression. Archives of General Psychiatry, 4, 561-571.

BIRNBAUM, M. H. (Ed.). (2000). Psychological experiments on the Internet. San Diego, CA: Academic Press.

BUCHANAN, T., \& SMITH, J. L. (1999). Using the Internet for psychological research: Personality testing on the World Wide Web. British Journal of Psychology, 90, 125-144.

CONDE, V., ESTEBAN, L., \& USEROS, E. (1976). Adaptación castellana de la escala de evaluación conductual para la depresión de Beck [Spanish adaptation of Beck's depression inventory]. Revista de Psicología General y Aplicada, 31, 496-497.

ELLIS, A. (1962). Reason and emotion in psychotherapy. Secaucus, NJ: Lyle Stuart.

FORGAS, J. P. (1998). On being happy and mistaken: Mood effects on the fundamental attribution error. Journal of Personality and Social Psychology, 75, 318-331.

FRANKEL, M. S., \& SIANG, S. (1999). Ethical and legal aspects of human subjects research in cyberspace. Report of a workshop convened by the American Association for the Advancement of Science, Program on Specific Freedom, Responsibility, and Law, Washington, DC. Retrieved May 9, 2005, from http://www.aaas.org/spp/dspp/sfrl/projects/intres/main.htm.

GOSLING, S. D., VAZIRE, S., SRIVASTAVA, S., \& JOHN, O. P. (2004). Should we trust Web-based studies? A comparative analysis of six preconceptions about Internet questionnaires. American Psychologist, 59, 93-104.

HAAGA, D. A. F., \& BECK, A. T. (1995). Perspectives on depressive realism: Implications for cognitive theory of depression. Behavior Research and Therapy, 33, 41-48.

KRAUT, R., OLSON, J., BANAJI, M., BRUCKMAN, A., COHEN, J., \& COUPER, M. (2004). Psychological research online: Report of board of scientific affairs' advisory group on the conduct of research on the Internet. American Psychologist, 59, 105-117.

LANGER, E. J. (1975). The illusion of control. Journal of Personality and Social Psychology, 32, 311-328.

LEWINSOHN, P. M. (1974). A behavioral approach to depression. In R. J. Friedman \& M. M. Katz (Eds.), The psychology of depression: Contemporary theory and research (pp. 176-178). Washington, DC: Wiley.

LEWINSOHN, P. M., SULLIVAN, J. M., \& GROSSCUP, S. J. (1980). Changing reinforcement events: An approach to the treatment of depression. Psychotherapy: Theory, Research, and Practice, 17, 322-333.

MATUTE, H. (1994). Learned helplessness and superstitious behavior as opposite effects of uncontrollable reinforcement in humans. Learning and Motivation, 25, 216-232. 
MATUTE, H. (1995). Human reactions to uncontrollable outcomes: Further evidence for superstitions rather than helplessness. Quarterly Journal of Experimental Psychology, 48B, 142-157.

MATUTE, H. (1996). Illusion of control: Detecting response-outcome independence in analytic but not in naturalistic conditions. Psychological Science, 7, 289-293.

MATUTE, H., VADILLO, M. A., \& BÁRCENA, R. (2007). Web-based experiment control software for research and teaching on human learning. Behavior Research Methods, 3, 689-693.

MATUTE, H., VADILLO, M. A., BLANCO, F., \& MUSCA, S. C. (2007). Either greedy or well informed: The reward maximization-unbiased evaluation trade-off. In Proceedings of the Second European Cognitive Science Conference (pp. 341-346). Mahwah, NJ: Erlbaum.

MATUTE, H., VADILLO, M. A., VEGAS, S., \& BLANCO, F. (2007). Illusion of control in Internet users and college students. Cyberpsychology \& Behavior, 10, 176-181.

MSETFI, R. M., MURPHY, R. A., \& SIMPSON, J. (2007). Depressive realism and the effect of inter-trial interval on judgments of zero, positive, and negative contingencies. Quarterly Journal of Experimental Psychology, 60, 461-481.

MSETFI, R. M., MURPHY, R. A., SIMPSON, J., \& KORNBROT, D. E. (2005). Depressive realism and outcome density bias in contingency judgments: The effect of the context and inter-trial interval. Journal of Experimental Psychology: General, 134, 10-22.

PLAUD, J. J., \& EIFERT, G. H. (1998). From behavior theory to behavior therapy. Boston: Allyn \& Bacon.

REHM, L. P. (1977). A-self control model of depression. Behavior Therapy, 8, 787-804.

REIPS, U-D. (2002). Standards for Internet-based experimenting. Experimental Psychology, 49, 243-256.

RUDSKI, J. M. (2000). Effect of delay of reinforcement on superstitious inferences. Perceptual and Motor Skills, 90, 1047-1058.

RUDSKI, J. M., LISCHNER, M. I., \& ALBERT, L. M. (1999). Superstitious rule generation is affected by probability and type of outcome. The Psychological Record, 49, 245-260.

SCHWARTZ, B. (1981). Does helplessness cause depression, or do only depressed people become helpless? Comment on Alloy and Abramson. Journal of Experimental Psychology: General, 110, 429-435.

SELIGMAN, M. E. P. (1975). Helplessness. San Francisco: Freeman.

SHANKS, D. R., \& DICKINSON, A. (1987). Associative accounts of causality judgment. In G. H. Bower (Ed.), The psychology of learning and motivation (Vol. 21, pp. 229-261). San Diego, CA: Academic Press.

SKINNER, B. F. (1948). "Superstition" in the pigeon. Journal of Experimental Psychology, 38, 168-172.

SKINNER, E. A. (1985). Action, control judgments and the structure of control experience. Psychological Review, 92, 39-58.

STADDON, J. E. R., \& SIMMELHAG, V. L. (1971). The "superstition" experiment: A reexamination of its implications for the principles of adaptive behavior. Psychological Review, 78, 3-43.

STEYVERS, M., TENENBAUM, J. B., WAGENMAKERS, E. -J., \& BLUM, B. (2003). Inferring causal networks from observations and interventions. Cognitive Science, 27, 453-489. 
TAYLOR, S. E., \& BROWN, J. D. (1988). Illusion and well-being: A social psychological perspective on mental health. Psychological Bulletin, 103, 192-210.

THOMPSON, S. C., ARMSTRONG, W., \& THOMAS, C. (1998). Illusions of control, underestimations and accuracy: A control heuristic explanation. Psychological Bulletin, 123, 146-161.

VADILLO, M. A., BÁRCENA, R., \& MATUTE, H. (2006). The Internet as a research tool in the study of associative learning: An example from overshadowing. Behavioural Processes, 73, 36-40.

VADILlO, M. A., \& MATUTE, H. (2007). Predictions and causal estimations are not supported by the same associative structure. Quarterly Journal of Experimental Psychology, 60, 433-447.

WARD, W. C., \& JENKINS, H. M. (1965). The display of information and the judgment of contingency. Canadian Journal of Psychology, 19, 231-241.

WASSERMAN, E. A. (1990). Detecting response-outcome relations: Toward an understanding of the causal texture of the environment. In G. H. Bower (Ed.), The psychology of learning and motivation (Vol. 26, pp. 27-82). San Diego, CA: Academic Press. 
Copyright of Psychological Record is the property of Psychological Record and its content may not be copied or emailed to multiple sites or posted to a listserv without the copyright holder's express written permission. However, users may print, download, or email articles for individual use. 